American Journal of Applied Sciences 6 (5): 978-986, 2009

ISSN 1546-9239

(C) 2009 Science Publications

\title{
Development of the Unified Series-Shunt Compensator for Power Quality Mitigation
}

\author{
M.A. Hannan, A. Mohamed, A. Hussain and Majid al Dabbay \\ Department of Electrical, Electronics and Systems, Faculty of Engineering, \\ National University Malaysia, 43600 UKM Bangi, Selangor DE, Malaysia
}

\begin{abstract}
This study describes the derivation of an analytical model and simulation for the unified series-shunt compensator (USSC) for investigating power quality in power distribution system. The USSC simulation comprises of two 12-pulse inverters which were connected in series and in shunt with the system. A generalized sinusoidal pulse width modulation (SPWM) switching technique was developed in the proposed controller for fast control action of the USSC. Simulations were carried out using the PSCAD/EMTDC electromagnetic transient programs to examine the performance of the USSC model. Simulation results from the proposed model demonstrated the performance of the USSC and its effectiveness for voltage sag compensation, flicker reduction, voltage unbalance mitigation, power flow control and harmonics elimination.
\end{abstract}

Key words: Unified series-shunt compensator; modeling; simulation; power quality mitigation

\section{INTRODUCTION}

Power quality issues have been attracting the attention of researches for decade. The increased concern has lead to measuring power quality variations, studying the characteristics of power disturbances and providing solutions to the power quality problems ${ }^{[1,2]}$. With the development of power electronic devices such as Flexible AC Transmission System (FACTS) and custom power devices, it has become possible to play an important role in emerging deregulated power systems with versatile new control capabilities ${ }^{[3-7]}$. In general, FACTS devices are used in transmission control whereas custom power devices are used for distribution control. Since the introduction of FACTS and custom power devices such as Unified Power Flow Controller (UPFC), synchronous static compensator (STATCOM), dynamic voltage restorer (DVR), solidstate transfer switch and solid-state fault current limiter have been are developed for improving power quality and reliability of a system ${ }^{[8-10]}$. Advanced control and improved semiconductor switching of these devices have reached a new era for power quality mitigation.

The FACTS and custom power devices have been developed for mitigating specific power quality problems. For example, UPFC works well for power flow control ${ }^{[11]}$, DVR which acts as a series compensator is used for voltage sag compensation and STATCOM which is a shunt compensator is used for reactive power and voltage sag compensation ${ }^{[12]}$. The STATCOM, DVR, UPS and active power conditioner are only useful for compensating a particular type of power quality problems ${ }^{[13-15]}$ and therefore, it has become necessary to develop a new kind of Unified Series-Shunt Compensator (USSC) which can mitigate a wider range of power quality problems. By using a unified approach of series-shunt compensators, it is possible to compensate for a variety of power quality problems in distribution systems including sag compensation, flicker reduction, unbalance voltage mitigation and power flow control. However, little work has been reported on the development of USSC.

The USSC is a combination of series and shunt Voltage Source Inverters (VSI) and its basic configuration is shown in Fig. 1. The basic components of the USSC are two 12-pulse voltage source inverters composed of forced commutated power semiconductor switches, typically Gate Turn Off (GTO) thyristor valves. One voltage source inverter is connected in series with the line through a set of series injection transformers, while the other is connected in shunt with the line through a set of shunt transformers. The dc terminals of the two inverters are connected together and their common dc voltage is supported by a capacitor bank ${ }^{[16]}$. Detailed description of the USSC is given in section 3 .

The USSC is almost similar to the UPFC, but the only differences are that the UPFC inverters are in

Corresponding Author: M.A. Hannan, Department of Electrical, Electronics and Systems, National University of Malaysia, Malaysia Tel: +6-03-89217014 Fax: +6-03-89216146 


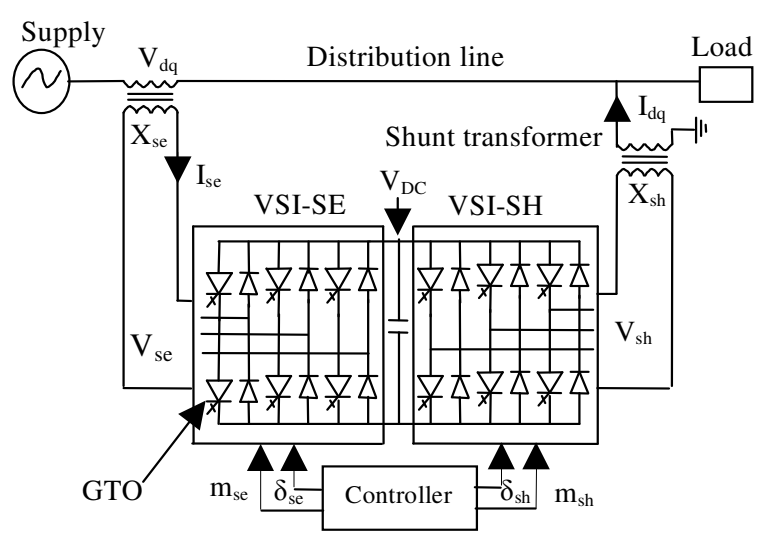

Fig. 1: Basic configuration of USSC

shunt-series connection and used in transmission systems whereas the USSC inverters are in series-shunt connection and used in distribution systems.

In this study, the derivation of simplified mathematical model and the capabilities of USSC in mitigating power quality problems issues are explored. The proposed model of the USSC considers the use of two 12-pulse inverters using sinusoidal pulse width modulation switching technique to achieve fast dynamic response of the USSC. The modeling and simulation of the USSC is carried out using the wellknown electromagnetic transient simulation program PSCAD/EMTDC.

\section{PRINCIPLE OPERATION OF USSC}

The principle operation of a USSC is described by the simplified model shown in Fig. 2.

The series connected inverter of the USSC injects a voltage, $\mathrm{V}_{\mathrm{dq}}$, in series with the distribution line, which in turn changes the voltage, $\mathrm{V}_{\mathrm{X}}$, across the distribution line reactance $X_{L}$ and hence changing the current and the power flow through the distribution line. The exchange of real power, $\mathrm{P}_{\text {inv }}$ and reactive power, $\mathrm{Q}_{\mathrm{inv}}$, can be written in terms of phase angle, $\phi$ (the angle between the injected voltage, $\mathrm{V}_{\mathrm{dq}}$ and the line current, $\mathrm{I}_{\mathrm{L}}$ ), the injected voltage $\mathrm{V}_{\mathrm{dq}}$ and the line current, $\mathrm{I}_{\mathrm{L}}$, as:

$$
\begin{aligned}
& P_{\text {inv }}=V_{d q} I_{L} \cos \phi \\
& Q_{\text {inv }}=V_{d q} I_{L} \sin \phi
\end{aligned}
$$

The current injected by the shunt inverter has a real or direct component, $I_{d}$, which can be in phase or in opposite phase with the line current and a reactive or quadrature component, $I_{q}$, which is in quadrature with

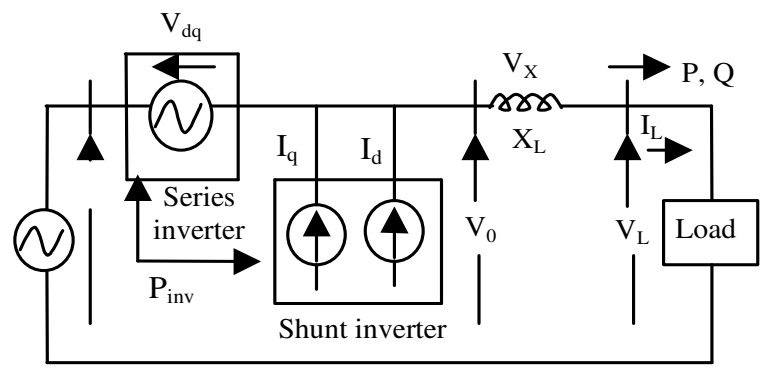

Fig. 2: Principle operation of USSC

the line current, thereby emulating an inductive or a capacitive reactance at the point of connection with the distribution line. The reactive current can be independently controlled which in turn will regulate the line voltage.

The USSC behaves as an ideal ac to ac inverter, in which the exchange of real power at the terminal of one inverter to the terminal of the other inverter is through the common dc link capacitor. It should be noted that shunt inverter is controlled in such a way as to provide precisely the right amount of real power at its dc terminal to meet the real power needs of the series inverter and to regulate the dc voltage of the dc bus. Thus, real power is absorbed from or delivered to the distribution line through the shunt connected inverter, which injects a current at the point of connection. Thus, USSC includes the functions of both series and shunt connected inverters which generates or absorbs reactive power to regulate voltage magnitude and current flow at the ac terminal, respectively ${ }^{[17]}$.

\section{MODEL OF USSC}

The modeling of the USSC can be divided into three parts, namely equivalent circuit model, controller model and simulation model, respectively, as described bellows:

Equivalent circuit model: In steady state analysis, the series and shunt inverters of the USSC are presented by two voltage sources $V_{d q}$ and $V_{\text {sh }}$, respectively as shown in Fig. 3. $X_{\mathrm{se}}$ and $\mathrm{X}_{\mathrm{sh}}$ are the reactances of the transformers associated with the series and shunt voltage sources inverter, respectively. Therefore, voltage equation of series and shunt inverter can be expressed as follows:

$$
\begin{gathered}
\mathrm{V}_{\mathrm{s}}=-\mathrm{V}_{\mathrm{dq}}+\mathrm{I}_{\mathrm{se}}\left(\mathrm{jX} \mathrm{se}_{\mathrm{se}}\right)+\mathrm{V}_{0} \\
\mathrm{~V}_{\mathrm{s}}+\mathrm{V}_{\mathrm{dq}}-\mathrm{I}_{\mathrm{se}}\left(j \mathrm{j}_{\mathrm{se}}\right)=\mathrm{V}_{\mathrm{sh}}+\mathrm{I}_{\mathrm{dq}}\left(\mathrm{X}_{\mathrm{sh}}\right)
\end{gathered}
$$




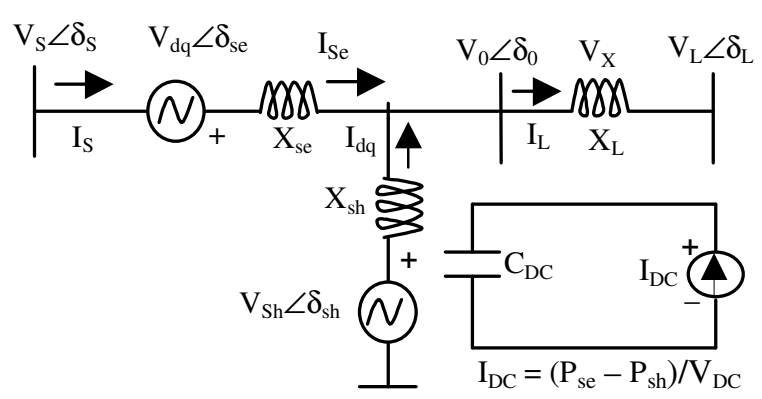

Fig. 3: Equivalent circuit of USSC

$$
I_{s}=I_{s e}-I_{d q}+I_{L}=\frac{V_{s h}-V_{0}}{X_{s h}}+I_{L}
$$

where, $I_{\mathrm{se}}$ and $\mathrm{I}_{\mathrm{dq}}$ are series and shunt inverter current, respectively.

The voltage across the distribution line reactance, $\mathrm{X}_{\mathrm{L}}$, is:

$$
\mathrm{V}_{\mathrm{X}}=\mathrm{V}_{\mathrm{s}}+\mathrm{V}_{\mathrm{dq}}-\mathrm{I}_{\mathrm{se}}\left(j \mathrm{X}_{\mathrm{se}}\right)-\mathrm{V}_{\mathrm{L}}=\mathrm{V}_{0}-\mathrm{V}_{\mathrm{L}}=\mathrm{I}_{\mathrm{L}} \mathrm{X}_{\mathrm{L}}
$$

where, $\mathrm{I}_{\mathrm{L}}$ is the distribution line current.

The voltage, $\mathrm{V}_{\mathrm{X}}$, across the distribution line can be changed by changing the inserting voltage, $\mathrm{V}_{\mathrm{dq}}$, in series with the distribution line and consequently, line current and power flows will be change. If we consider $\mathrm{V}_{\mathrm{dq}}=0$, the distribution line sending end voltage, $\mathrm{V}_{\mathrm{s}}$, leads the load voltage by an angle $\delta$ i.e., $\delta=\delta_{\mathrm{S}}-\delta_{\mathrm{L}}$. The resulting real and reactive power flows to the load are $\mathrm{P}$ and $\mathrm{Q}$, respectively as follows:

$$
\begin{aligned}
& \mathrm{P}=\frac{\mathrm{V}_{0} \mathrm{~V}_{\mathrm{L}}}{\mathrm{X}_{\mathrm{L}}} \sin \delta \\
& \mathrm{Q}=\frac{\mathrm{V}_{0} \mathrm{~V}_{\mathrm{L}}}{\mathrm{X}_{\mathrm{L}}}(1-\cos \delta)
\end{aligned}
$$

With an injection of $\mathrm{V}_{\mathrm{dq}}$, the distribution line voltage injection of $\mathrm{V}_{\mathrm{dq}}$ still leads the load voltage $\mathrm{V}_{\mathrm{L}}$, i.e., $\delta_{0}>\delta_{\mathrm{L}}$, resulting the line current and amount of flow will change. With a larger amount of $\mathrm{V}_{\mathrm{dq}}$ injection, $\mathrm{V}_{0}$, now lags the load voltage $\mathrm{V}_{\mathrm{L}}$, i.e., $\delta_{0}<\delta_{\mathrm{L}}$. Consequently, line current and power flow will be reversed.

If the control system design together with sinusoidal pulse width modulated switching is adopted for the GTO-based voltage source inverter of the USSC, where the resistance and the transients of the transformers are not considered, the dynamic model of the DC link of the USSC is as follows:

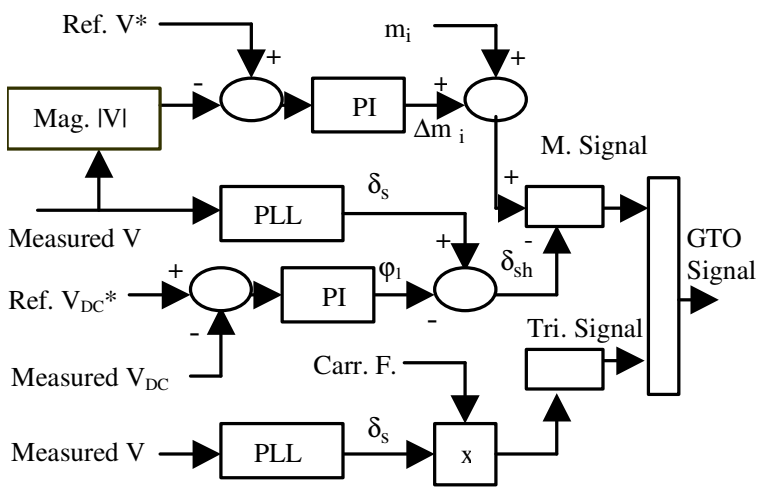

Fig. 4: Shunt inverter control model of USSC

$$
\frac{\mathrm{dV}_{\mathrm{DC}}}{\mathrm{dt}}=\frac{1}{\mathrm{C}_{\mathrm{DC}}} \mathrm{I}_{\mathrm{DC}}=\frac{1}{\mathrm{C}_{\mathrm{DC}} \mathrm{V}_{\mathrm{DC}}}\left(\mathrm{P}_{\mathrm{se}}-\mathrm{P}_{\mathrm{sh}}\right)
$$

where, $P_{\mathrm{sh}}=\operatorname{Re}\left[\frac{\mathrm{V}_{\mathrm{sh}}\left(\mathrm{V}_{\mathrm{s}}-\mathrm{V}_{\mathrm{sh}}\right)}{\mathrm{j} \mathrm{X}_{\mathrm{sh}}}\right]$

$$
P_{s e}=\operatorname{Re}\left[V_{d q}\left(\frac{\left.V_{s}+V_{d q}-V_{0}\right)}{j X_{s e}}\right]\right.
$$

Controller model: In the control system design, SPWM switching technique is adopted for the GTObased inverters of the USSC. In this model, the triangular carrier signal, $\mathrm{V}_{\mathrm{m}, \text { tri }}$, is compared with the voltage-modulating signal, $\mathrm{V}_{\mathrm{m} \text {,sin }}$, so as to obtain the firing signals of the GTOs. Therefore, the amplitude modulation index is defined as follows ${ }^{[18-20]}$.

$$
\mathrm{m}_{\mathrm{a}}=\frac{\mathrm{V}_{\mathrm{m}, \mathrm{sin}}}{\mathrm{V}_{\mathrm{m}, \mathrm{tri}}}
$$

The controller of the shunt inverter is used to operate the voltage source inverter in such a way that the phase angle between the inverter voltage and the line voltage is adjusted over a wide range so that the shunt inverter generates or absorbs reactive power at the point of connection to the system. Fig. 4 illustrates the control of the shunt inverter configuration together with SPWM switching as implemented in PSCAD/EMTDC.

In the voltage control loop, the measured threephase voltages are fed to the Phase Locked Loop (PLL) in order to detect the phase angles and angular positions of the voltages. The PLL is responsible for providing the voltage synchronizing signal with an angle $\delta_{\mathrm{s}}$.

The dc control loop measures dc link capacitor voltage, $\mathrm{V}_{\mathrm{DC} \text { and }}$ compared with its reference input $\mathrm{V}_{\mathrm{DC}}{ }^{*}$. 
The difference observed is fed to the PI controller. The output of the PI controller is the firing angle $\varphi_{1}$ of the shunt inverter of the USSC. The synchronizing signal $\delta_{\mathrm{s}}$ minus the firing angle $\varphi_{1}$ gives the angle of SPWM output signal $\delta_{\mathrm{sh}}$ in which its phase is controlled:

$$
\begin{gathered}
\varphi_{1}=\left(\mathrm{K}_{\mathrm{p}}+\frac{\mathrm{K}_{\mathrm{s}}}{\mathrm{s}}\right) \times\left(\mathrm{V}_{\mathrm{DC}}{ }^{*}-\mathrm{V}_{\mathrm{DC}}\right) \\
\delta_{\mathrm{sh}}=\delta_{\mathrm{s}}-\varphi_{1}
\end{gathered}
$$

To control the shunt connected inverter bus voltage, the measured voltage magnitude $|\mathrm{V}|$ is compared with its reference value $\mathrm{V}^{*}$ and passed to the PI controller to produce modulation index designated as $\Delta \mathrm{m}_{\mathrm{i}}$. Finally, the part which generate the modulating index SPWM output signal, $\mathrm{m}_{\mathrm{sh}}$ is calculated as follows:

$$
\begin{gathered}
\Delta \mathrm{m}_{\mathrm{i}}=\left(\mathrm{K}_{\mathrm{p}}+\frac{\mathrm{K}_{\mathrm{s}}}{\mathrm{s}}\right) \times\left(\mathrm{V}^{*}-|\mathrm{V}|\right) \\
\mathrm{m}_{\mathrm{sh}}=\mathrm{m}_{\mathrm{i}}+\Delta \mathrm{m}_{\mathrm{i}}
\end{gathered}
$$

The PLL provides a voltage synchronizing signal, $\delta_{\mathrm{s}}$, multiplied by a carrier frequency of $1.65 \mathrm{kHz}$, which is 33 times the system operating frequency so as to convert the carrier ramp signal into a triangular carrier signal whose amplitude is fixed between -1 to +1 .

Using $\delta_{\mathrm{sh}}$ and $\mathrm{m}_{\mathrm{sh}}$, the SPWM output modulating signal, $\mathrm{V}_{\sin 1}$ is derived whcin is compared with the triangular signal so that gating pulses of the GTO can be produced.

$$
\mathrm{V}_{\mathrm{sin} 1}=\mathrm{m}_{\mathrm{sh}} \cos \delta_{\mathrm{sh}}
$$

Therefore, the fundamental component of the shunt inverter output voltage is defined as follows:

$$
\mathrm{V}_{\mathrm{sh}}=\mathrm{m}_{\mathrm{sh}} \mathrm{V}_{\mathrm{DC}} \cos \delta_{\mathrm{sh}}
$$

If $\delta_{\text {sh }}=0$, the shunt inverter output voltage is said to be in phase with the ac system voltage. However, if there is an error between the synchronizing signal and the firing angle, that is, $\delta_{\mathrm{s}}>\varphi_{1}$, then the displacement angle $\delta_{\text {sh }}>0$ and the shunt inverter voltage lags behind the ac system voltage thus causing real power flow into the shunt inverter. Consequently, the dc capacitor voltage will increase, thus causing an increase in the ac output voltage of the shunt inverter. The increase in ac output voltage causes a reduction in the error voltage until $\delta_{\mathrm{s}}=\varphi_{1}$. If $\delta_{\mathrm{s}}<\varphi_{1}$, then the displacement angle $\delta_{\mathrm{sh}}<0$ and the shunt inverter voltage leads the ac voltage thus causing real power flow into the system. Consequently, the dc capacitor voltage will decrease, thus causing a decrease in the ac output voltage of the shunt inverter and a reduction in the error voltage until $\delta_{\mathrm{s}}=\varphi_{1}$. Thus, the inverter output voltage can be controlled by controlling amplitude modulation and the angle $\delta_{\text {sh }}$.

The control for the series inverter is almost similar to that of the shunt inverter, but the only difference is that in the series inverter control loop, the measured phase currents are the input to the PLL in order to generate the synchronizing signals. The series inverter injected voltages are kept in quadrature with the line currents to provide series compensation, whereas in the shunt inverter injected currents are kept in quadrature with the line voltage. In the series inverter control, the generation of the synchronizing signal $\delta_{\text {se }}$, firing angle $\varphi_{2}$, triangular carrier signal, modulating index $\mathrm{m}_{\mathrm{se}}$ and voltage modulated signal $\mathrm{V}_{\sin 2}$ are similar to that of the shunt inverter. In general, the overall controller function is the same to that of the shunt inverter controller. Therefore, we can write:

$$
\begin{array}{r}
\delta_{\mathrm{se}}=\delta_{\mathrm{s}}-\varphi_{2} \\
\mathrm{~V}_{\mathrm{se}}=\mathrm{m}_{\mathrm{se}} \mathrm{V}_{\mathrm{DC}} \cos \delta_{\mathrm{se}}
\end{array}
$$

Simulation model: The simulation model of the USSC is developed using the PSCAD/EMTDC electromagnetic transient simulation programme as shown in Fig. 5. The USSC consist of two 12-pulse inverters in which one 12-pulse inverter is connected in

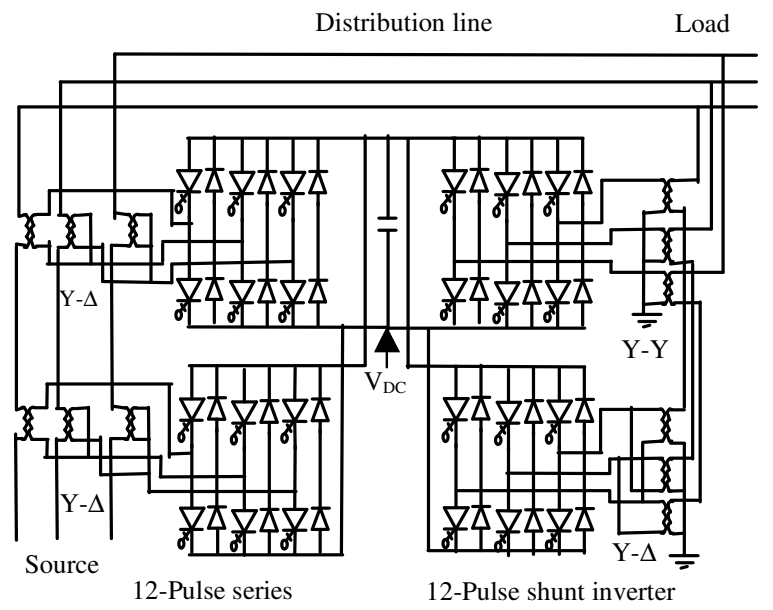

Fig. 5: Simulation model of USSC using 12-pulse series and shunt inverters 
series and the other 12-pulse inverter is connected in shunt. The series and shunt combination of inverters consist of two levels, three phase, twenty-four selfcommutated GTO switches with anti-parallel diodes. This GTO switch combination and its capability to act as a rectifier or as an inverter with instantaneous current flows in forward or backward direction, respectively, constitutes the basic voltage source converter concept. The shunt connected inverter is connected to the load by means of two sets of three single-phase transformers which are of $\mathrm{Y}-\mathrm{Y}$ and $\mathrm{Y}-\Delta$ configurations to avoid phase shift of other than the order of $12 \mathrm{n} \pm 1$ harmonics in the secondary of the transformers, which may result in large circulating current due to common core. The phase to neutral harmonic voltages of Y-Y connected secondary, other than the order of $12 \mathrm{n} \pm 1$, i.e., 5 th, 7 th, 17th, 19th.... are opposite to those of the phase to phase harmonic voltages of $\mathrm{Y}-\Delta$ connected secondary and are $1 / 3$ times the amplitude. The output voltage of the shunt inverter would be a 12-pulse wave form, with harmonic order of $12 \mathrm{n} \pm 1$. However, the series connected inverter is connected to the source by means of two sets of three single-phase transformers which are of $\mathrm{Y}-\Delta$ configuration. This is because, usually $\mathrm{Y}$-connected secondary windings allow the injection of positive, negative and zero sequence voltages, whereas the delta connected secondary windings allow only the injection of positive and negative sequence voltages. The delta connection prevents zero sequence currents entering into the system from the inverter.

The primary windings of all the single-phase transformers are connected in series in order to avoid harmonic circulating current. The leakage reactance of the all the transformers are kept low so as to prevent a large voltage drop. The $22 / 4.6 \mathrm{kV}$ step-down transformers with a leakage reactance of 0.01 per unit are considered. Two consecutive 6-pulse inverters are used to configure the 12-pulse inverter and the phase shift between these two inverters is calculated and found to be 30 degrees by using the phase shift displacement angle formula which is given by $2 \pi / 6 \mathrm{~m}$, where $\mathrm{m}$ is the number of the 6-pulse inverters used. The capacitor plays an important role in the USSC operation by acting as a dc source to provide reactive power to the system and to regulate the dc voltage. The size of the dc capacitor considered in this simulation is $3340 \mu \mathrm{F}$.

\section{RESULTS AND DISCUSSIONS}

The performance of the USSC model is evaluated by means of simulation techniques using the
PSCAD/EMTDC transient simulation program. The USSC is connected to a $22 \mathrm{kV}$ distribution system with a static load of 5.2 MVA, 0.90 power factor. There are twelve single-phase transformers with each rated at 1 MVA, 22/4.16 $\mathrm{kV}$ and a leakage reactance of 0.01 p.u. connecting the USSC to the distribution system. Simulations is carried out to illustrate the effectiveness of the USSC as a unified compensator for voltage regulation, voltage sag compensation, voltage flicker reduction and voltage unbalance mitigation, as described below.

USSC for voltage sag compensation: To illustrate the use of the USSC to compensate voltage sags, a voltage sag condition is simulated by creating a balanced threephase to ground fault using a three-phase fault generator. Simulation results showing the use of USSC for compensating voltage sags are shown in Fig. 6 in terms of the load voltage in per unit.

For the system without the USSC, the load voltage drops from 1.0 p.u to 0.50 p.u as shown in Fig. 6a. This is a voltage sag condition which is due to a three-phase fault created at time $t=1.5 \mathrm{~s}$ for a duration of $0.75 \mathrm{sec}$. For the system with the USSC connected, the load voltage increases from 0.50 p.u to 1.0 p.u as shown in Fig. $6 \mathrm{~b}$. The load voltage returns to its rated value due to the voltage sag compensation capability of the USSC. Fig. $6 \mathrm{~b}$ also shows that the load ripple voltage at the starting and the ending of compensation are due to the charging and discharging of the USSC capacitor
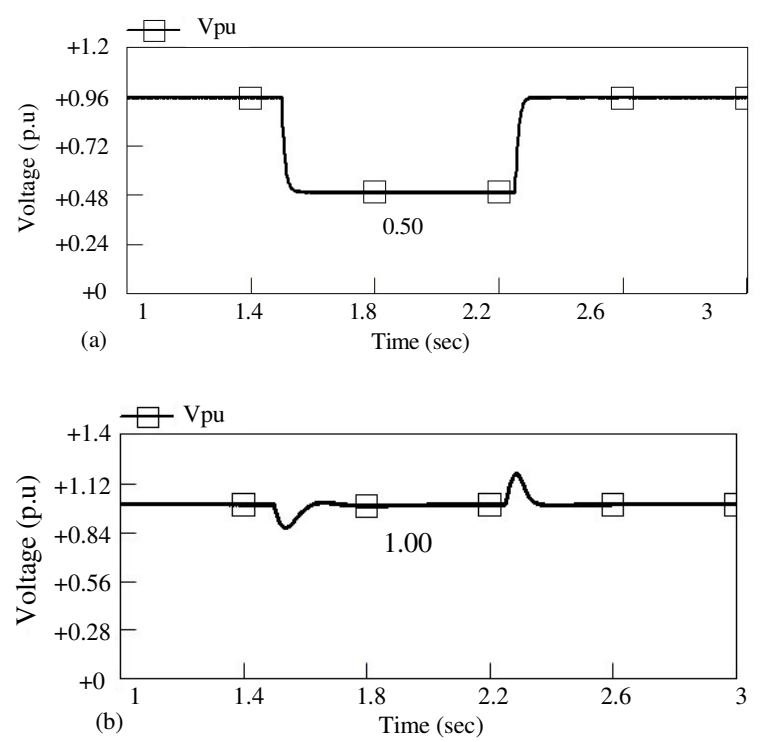

Fig. 6: Load voltages (a): Without USSC (b): With USSC 

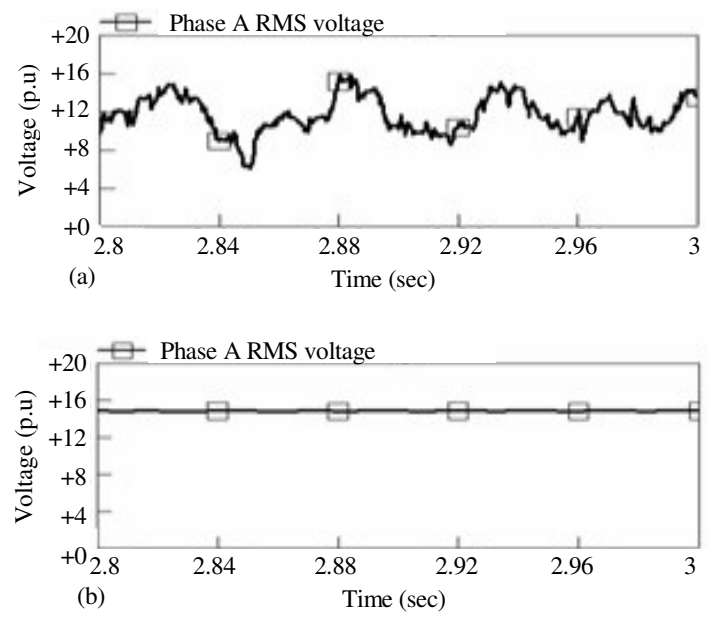

Fig. 7: RMS Voltage flicker, (a): Without USSC (b): With USSC connected

bank. It is concluded from the simulation results obtained that the USSC shows a better voltage sag compensation capability as compared to the DVR and the D-STATCOM in terms of the voltage magnitudes $^{[21]}$.

USSC for voltage flicker reduction: Voltage flicker is a phenomenon of light intensity fluctuation causeds by different reason such as variable electric loads and arc furnaces, has been one of the major power quality concern. To illustrate the effectiveness of using the USSC in reducing voltage flicker, simulation studies is carried. A variable electric load of 5.2 MVA, $22 \mathrm{kV}$ and 0.90 power facor has been assumed as the source of voltage flicker. Figure 7a shows the flicker effect of the phase rms voltage for the system without the USSC connected. The system with USSC connected, the simulation result shows that the rms voltage of phase A is flicker free as shown in Fig. 7b. Although the results in this study are given for the response in phase A only, similar results were found for the other two phases.

Many techniques have been proposed in literature for evaluating the voltage flicker levels. In this simulation method, voltage flicker level is calculated using FFT technique. The obtained result shows that without USSC connected, the effect of variable electric load gave a voltage flicker index of 0.40 which exceeds the IEEE standard limit of 0.07 . However, with the USSC connected, it is found that the calculated voltage flicker index is reduced to 0.002 .

USSC for voltage unbalance mitigation: Voltage unbalance causes heating of motors, thus it is important to maintain balanced three phase voltages. Unbalance
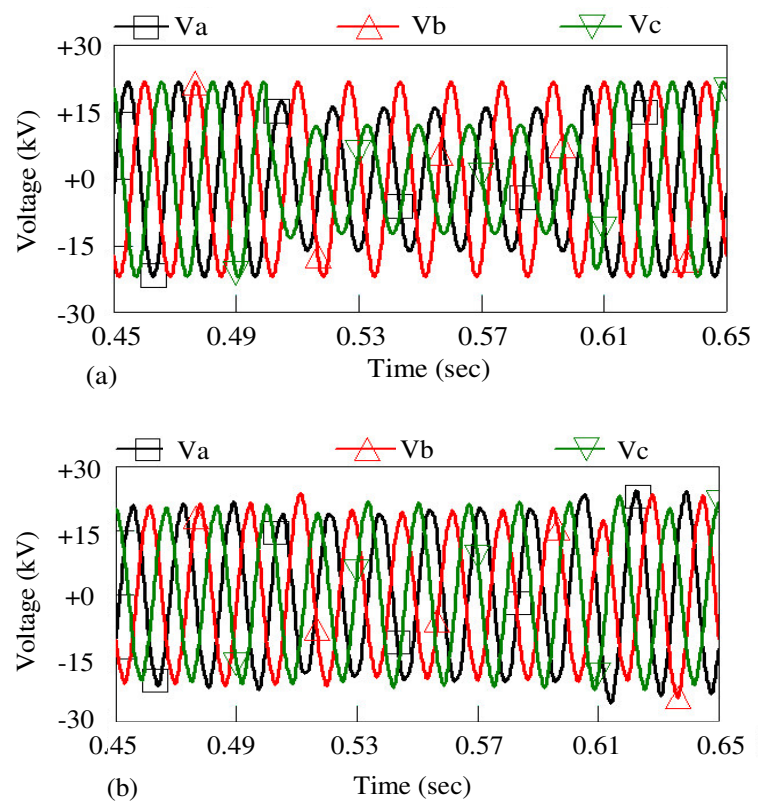

Fig. 8: Three-phase load voltages (a): Without USSC (b): With USSC

can also affect sensitive single phase loads because it creates under voltage in one or more of the lines. Therefore, it is important to investigate the effectiveness of USSC in mitigating voltage unbalance. Hence, in this simulation, initially an unbalanced voltage condition is created by applying two single phase to ground faults on phase $\mathrm{A}$ and phase $\mathrm{C}$ at time $\mathrm{t}=0.5 \mathrm{~s}$ for a fault duration of $100 \mathrm{~ms}$. Figure $8 \mathrm{a}$ shows the simulation results of the three-phase unbalanced voltages for the system without the USSC connected. It can be seen that during the fault condition, maximum phase voltages are $\mathrm{V}_{\mathrm{a}}=14.5 \mathrm{kV}, \mathrm{V}_{\mathrm{b}}=19.21 \mathrm{kV}$ and $\mathrm{V}_{\mathrm{c}}=10.5 \mathrm{kV}$. The percentage of voltage unbalance is calculated and found to be $28.7 \%$. This value indicates that the voltage unbalance is severe during the fault, because the limit of the voltage unbalance is specified as $2 \%$ in the IEEE Std. 1159.

With the application of USSC, 3-phase load voltages are recorded as shown in Fig. 8b. It is evident from this figure that in the presence of the USSC, the 3phse load voltages have been balanced by increasing the magnitudes of phase $\mathrm{A}$ and $\mathrm{C}$ voltages and reducing the magnitude of phase $\mathrm{B}$ voltage.

The percentage of voltage unbalance decreased from $28.7-1.6 \%$, which is below the value specified in IEEE standard. Though the D-STATCOM can reduce voltage unbalance moderately, however, DVR is almost unable to reduce the unbalance of the system ${ }^{[3]}$. 

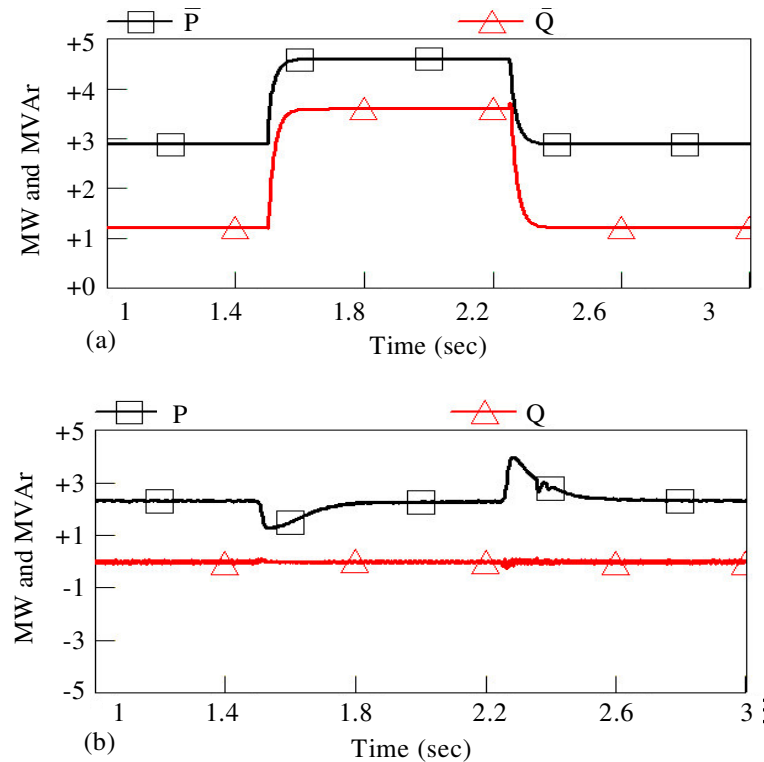

Fig. 9: Active and reactive power flows (a): Without USSC (b): With USSC

USSC for power flow control: The flows of instantaneous active and reactive powers into or out of the USSC are investigated using the transient simulation program. When a fault occurs in the distribution system at time $\mathrm{t}=1.5 \mathrm{sec}$ for a duration $0.75 \mathrm{sec}$, the active and reactive power flow into the system are given in Fig. 9a. Simulation results indicate that during the fault period, both the active and reactive powers of the system increase. From the USSC operation point of view, the increase in the reactive power requires an increase in the active power injected by the series inverter of the USSC and an increase in the active power supplied by the shunt inverter of the USSC. The exchange of real power can be made in either direction between the series and shunt inverters of the USSC. With the USSC connected in the system, the reactive power of the system is reduced from 1.2 MVAr to zero in order to achieve a steady state value of active power as shown in Fig. 9b. Thus, the active and reactive power flows are controlled and maintain at a pre-fault levels.

Harmonic elimination: Simulation results shown in Fig. 10a indicate that the USSC inverters generate a voltage with total harmonic distortion (THD) of $78 \%$. Due to high frequency switching losses, the inverters have generated a THD which is higher than the acceptable level of $5 \%$. Therefore, filtering is indispensable so as to eliminate the harmonics generated by the USSC. Several methods can be used
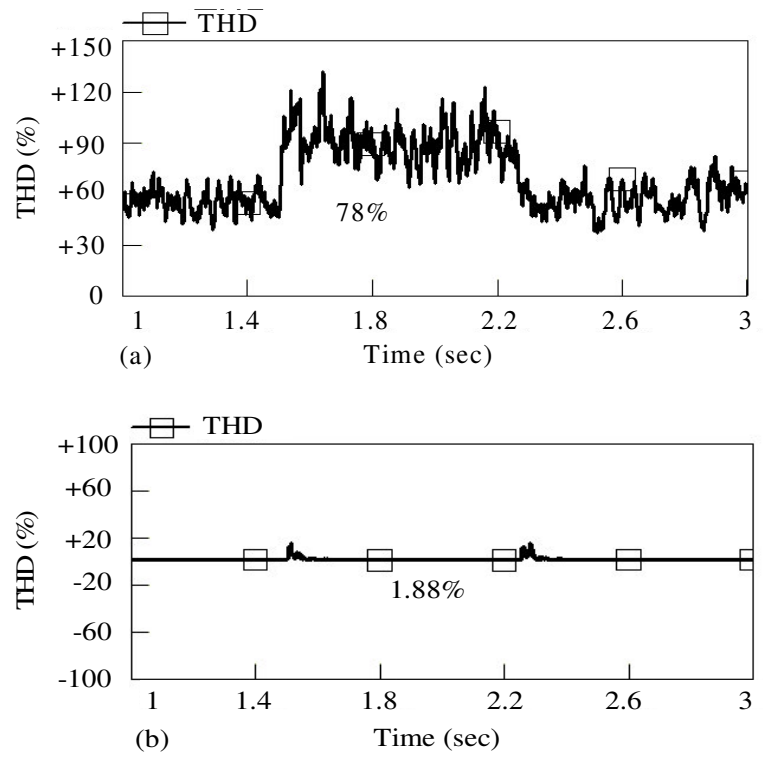

Fig. 10: Total harmonic distortion (a): Without filter (b): With filter

Table 1: PQ Mitigation of USSC vs. D-STATCOM and DVR

\begin{tabular}{llll}
\hline PQ mitigation & DVR & D-STATCOM & USSC \\
\hline Sag compensation & Yes & Limited & Yes \\
Voltage flicker & No & Yes & Yes \\
Unbalance & No & Yes & Yes \\
UPS mode & Yes & Yes & Yes \\
Power flow control & No & No & Yes \\
Harmonic elimination & No & Yes & Yes \\
\hline
\end{tabular}

for reducing the harmonics produced by the USSC. In this simulation, a passive filter is connected at the load side of the distribution system. To illustrate the effect of using an LC passive filter, simulations were carried out and the THD of the system with the filter is recorded as shown in Figs. 10b. From the simulation results, it can be seen that with the filters connected, the harmonics are suppressed and the THD of the system is reduced from $78 \%$ to $1.88 \%$ which is below the value of the IEEE standard THD limit of 5\%. The parameters of the passive filter considered in the simulation are: $\mathrm{L}=0.3 \mathrm{H}$ and $\mathrm{C}=35 \mu \mathrm{F}$.

Capabilities of USSC vs. D-STATCOM and DVR: Usually individual custom power devices such as DSTATCOM and DVR focus on solving specific power quality problems in a distribution system. However, by using USSC, it is possible to compensate a different power quality problem as compared to D-STATCOM and DVR as indicated in Table 1.

It is noted that, mitigated load voltage by the DVR is a steady state value, however in case of voltage flicker, unbalance and harmonics elimination it is not 
much effective. Similarly, D-STATCOM is unable to control power flow. It is seen that the proposed USSC can mitigate variety of PQ problems.

\section{CONCLUSION}

The mitigation of a number of power quality problems have been investigated by using USSC. The two level USSC incorporating 12-pulse series and shunt connected inverters has been modeled in PSCAD/EMTDC program and a new SPWM-based control scheme has been implemented to control the GTOs of the inverters. Simulations have been carried out to evaluate the performance of the USSC under various operating conditions and power quality disturbances. Simulation results revealed that the USSC can mitigate effectively voltage sag, flicker reduction, voltage unbalance and power flow control. It was also shown that harmonics generated by the USSC can be significantly reduced by connecting a passive filter to the system. The results revealed that the USSC gives a better performance in power quality mitigation especially in voltage sag compensation and power flow control and also provide more power quality solutions as compared to the D-STATCOM and DVR.

\section{ACKNOWLEDGEMENT}

The authors would like to thank the Malaysian Ministry of Science Technology and Innovation (MOSTI) for funding this work research grant IRPA 03-02-02-0017-SR0003/07-03.

\section{REFERENCES}

1. Oliver, J.A., R. Lawrence and B.B. Banerjee, 2002. How to specify power-quality-tolerant process equipment. IEEE Ind. Appl. Magazine, 8: 21-30. DOI: 10.1109/MIA.2002.1028387.

2. Shin, Y.J., E.J. Powers, M. Grady and A. Arapostathis, 2006. Power quality indices for transient disturbances. IEEE Trans. Power Delivery, 21: 253-261. DOI: 10.1109/TPWRD. 2005.855444.

3. Enslin, J.R., 1998. Unified approach to power quality mitigation. In: Proceeding of IEEE International Symposium on Industrial Electronics (ISIE '98), 1998, pp: 8-20. DOI: 10.1109/ISIE.1998.707741.

4. Singh, B., K. Al-Haddad and A. Chandra, 1999. A review of active filters for power quality improvement. IEEE Trans. Ind. Elect., 46: 960-971. DOI: 10.1109/41.793345.
5. Crow, M.L., 2004. Power quality enhancement using custom power devices. IEEE Power Energy Magazine, 42 : 50-56. DOI: 10.1109/MPAE.2004.1269618.

6. Ramirez, J.M., J.M. Gonzalez and M.L. Crow, 2007. Steady state formulation of FACTS devices based on ac/ac converters. IET Generat. Transmission Distribut., 1: 619-631. DOI: 10.1049/iet-gtd:20060329.

7. Zarghami, M. and M.L. Crow, 2007. The existence of multiple equilibria in the upfc power injection model. IEEE Trans. Power Syst., 22: 2280-2282. DOI: 10.1109/TPWRS.2007.907588.

8. Pohjanheimo, P. and E. Lakervi, 2000. Steady state modeling of custom power components in power distribution networks. In: IEEE Power Engineering Society Winter Meeting, pp: 2949-2954. DOI: 10.1109/PESW.2000.847354.

9. Parle, J.A., M. Madrigal and E. Acha, 2001. Trends in power quality monitoring. IEEE Power Eng. Rev., 21: 3-21. DOI: 10.1109/39.954584.

10. Olimpo, A.L and E. Acha, 2002. Modelling and analysis of custom power systems by PSCAD/EMTDC. IEEE Trans. Power Delivery, 17: 266-272. DOI: $10.1109 / 61.974217$.

11. Arnez, R.L. and L.C. Zanetta, 2002. Unified power flow controller (UPFC): Its versatility in handling power flow and interaction with the network. In: IEEE/PES Asia Pacific Transmission and Distribution Conference and Exhibition, pp: 1338 -1343. http://www.ieeexplore.iee. $\mathrm{org} / \mathrm{xpl} /$ tocresult.jsp?isnumber $=26430$ \&isYear $=20$ 02[15 March, 2008]

12. Hingorani, N.G. and L. Gyugyi, 2000. Understanding FACTS Concept and Technology of Flexible AC Transmission System. IEEE Press, New York.

13. Su, C. and G. Joos, 2000. Series and shunt active power conditioners for compensating distribution system faults. In: Procedding of the Canadian Conference on Electrical and Computer Engineering, pp: 1182-1186. DOI: 10.1109/CCECE.2000.849650.

14. le Roux, A.D., H.T. Mouton and H. Akagi, 2003. Digital control of an integrated series active filter and diode rectifier with voltage regulation. IEEE Trans. Ind. Appl., 39: 1814-1820. DOI: 10.1109/TIA.2003.819440.

15. Kincic, S., X.T. Wan, D.T. McGillis, A. Chandra, O. Boon-Teck, F.D. Galiana and G. Joos, 2005. Voltage support by distributed static VAr systems (SVS). IEEE Trans. Power Delivery, 20: 1541-1549. DOI: 10.1109/TPWRD. 2004.838640 
16. Soto-Sanchez, D.E. and T.C. Green, 2001. Voltage balance and control in a multi-level unified power flow controller. IEEE Trans. Power Delivery, 16: 732-738. DOI: 10.1109/61.956763.

17. Gyugyi, L., K.K. Sen and C.D. Schauder, 1999. The interline power flow controller concept: A new approach to power flow management in transmission systems. IEEE Trans. Power Delivery, 14: 1115-1123. DOI: 10.1109/61.772382.

18. Song, Y.H. and A.T. Johns, 1999. Flexible AC Transmission Systems (FACTS). IEE Power Energy Series, 30.

19. Ying, X., Y.H. Song and Y.Z. Sun, 2002. Power flow control approach to power systems with embedded FACTS devices. IEEE Trans. Power Syst., $\quad 17$ : 943-950. 10.1109/TPWRS.2002.804919.
20. Bie, Z.H., Y.H. Song, X.F. Wang, G.A. Taylor and M.R. Irving, 2006. Integration of algorithmic and heuristic techniques for transition-optimized voltage and reactive power control. IEE Proc. Generat. Transmission Distribut., 153: 205-210. DOI: 10.1049/ip-gtd:20050019.

21. Hannan, M.A. and A. Mohamed, 2002. Modelling and analysis of a 24-pulse dynamic voltage restorer in a distribution system. In: Proceeding of IEEE 2nd Student Conference on Research and Dev. (SCOReD), Shah Alam, Malaysia, pp: 192-195. DOI: 10.1109/SCORED.2002.1033090. 